\title{
Calcium regulation of $\mathrm{HCN}$ supports persistent activity associated with working memory: a multiscale model of prefrontal cortex
}

\author{
Samuel A Neymotin ${ }^{1 *}$, Robert A McDougal ${ }^{2}$, Michael Hines ${ }^{2}$, William W Lytton ${ }^{1,3}$ \\ From The Twenty Third Annual Computational Neuroscience Meeting: CNS*2014 \\ Québec City, Canada. 26-31 July 2014
}

The Hyperpolarization-activated cyclic-nucleotide gated channel (HCN; $I_{h}$ current) has been hypothesized to facilitate short-term memory storage in the prefrontal cortex (PFC) via a cascade of signalling events involving second messengers including protein kinases and intracellular calcium $(\mathrm{Ca})$ accumulation [1]. This memory mechanism is effected via alterations in the dynamics of the network, two scales above the underlying molecular level. To determine the factors that enable persistent activity to emerge, we developed a multiscale model (molecular to network level) of PFC that displays the persistent activity associated with working memory.

The network contained 800 cells arranged in 6 neocortical layers. Cell classes included pyramidal cells, and fast-spiking and low-threshold-spiking interneurons. Each neuron contained $\mathrm{Na}, \mathrm{K}, \mathrm{Ca}$, and $\mathrm{HCN}$ channels. Cells were interconnected probabilistically using detailed anatomical data from M1, with AMPA/NMDA, and GABAA synapses. Intracellular $\mathrm{Ca}$ was admitted via NMDA and L-type Ca channels. Intracellular signaling components which contributed to persistent activity included: diffusible $\mathrm{Ca}$, diffusible $\mathrm{Ca}$ buffering proteins, intracellular endoplasmic reticulum (ER) compartments for sequestering Ca, diffusible inositol triphosphate (IP3), ER IP3 receptors (IP3R) which release Ca from ER upon IP3/Ca binding, sarco/endoplasmic reticulum Ca-ATPase pumps (SERCA) which pump cytosolic $\mathrm{Ca}$ into the ER, Ca/IP3 degradation reactions. Pyramidal cells had $\mathrm{HCN}$ channels regulated by protein kinases bound to intracellular $\mathrm{Ca}$. The model was implemented in parallel NEURON with reaction-diffusion [2]. 18 seconds of

\footnotetext{
* Correspondence: samn@neurosim.downstate.edu

'Department of Physiology \& Pharmacology, SUNY Downstate, Brooklyn, NY, 11203, USA

Full list of author information is available at the end of the article
}

simulation time ran over 24 Intel XEON CPUs in $\sim 7$ minutes.

We assessed influences between intracellular signaling and network dynamics to isolate sources needed for emergence of short-term memory representations. We provided excitatory stimuli to a subset of pyramidal cells which represented the memory. Stimulus-induced depolarization led to $\mathrm{Ca}$ influx which increased $\mathrm{HCN}$ conductance and excitability of the stimulated population (firing increased from $0.5-2 \mathrm{~Hz}$ ). Activation of the stimulated population lasted for 5-10 seconds and also increased beta/gamma $(\sim 15-35 \mathrm{~Hz})$ oscillations. In contrast, nonstimulated populations were suppressed (firing rate reduction up to $50 \%$ ) due to higher inhibition caused by the activated cells providing stronger drive to the interneurons. Knocking out specific pathways showed that persistent activity of activated cells was only viable in the presence of $\mathrm{Ca}$ influx, Ca regulation of $\mathrm{HCN}$ channels, and interactions between excitatory and inhibitory populations, which led to network-derived inhibition activating HCN. Lowering concentrations and binding rates of Ca buffering proteins reduced the network's ability to represent specific inputs, due to the higher levels of intracellular Ca saturating $\mathrm{HCN}$ channels in all pyramidal neurons. This predicts that $\mathrm{Ca}$ buffering proteins contribute to regulation of $\mathrm{Ca}$ at time-scales relevant for maintaining distinct short-term memory representations. We also used our model to demonstrate nonsynaptic plasticity - initial stimuli cause Ca sequestration in the ER of activated neurons, allowing for later, selective modulation of their excitability via metabotropic glutamate receptor activation of IP3Rs, which releases the stored Ca. Our model demonstrates how electro-chemical interactions at the nanoscale may lead to network consequences that 
produce persistent activity associated with working memory.

\section{Acknowledgments}

Research supported by NIH grant R01 MH086638.

\section{Authors' details}

'Department of Physiology \& Pharmacology, SUNY Downstate, Brooklyn, NY, 11203, USA. 'Department of Neurobiology, Yale Medical School, New Haven, CT, 06510, USA. ${ }^{3}$ Department of Neurology, Kings County Hospital Center, Brooklyn, NY, 11203, USA.

Published: 21 July 2014

\section{References}

1. Winograd M, Destexhe A, Sanchez-Vives MV: Hyperpolarization-activated graded persistent activity in the prefrontal cortex. PNAS 2008, 105(20):7298-7303.

2. McDougal RA, Hines ML, Lytton WW: Reaction-diffusion in the NEURON simulator. Front Neuroinformatics 2013, 7:28

doi:10.1186/1471-2202-15-S1-P108

Cite this article as: Neymotin et al: Calcium regulation of HCN supports persistent activity associated with working memory: a multiscale model of prefrontal cortex. BMC Neuroscience 2014 15(Suppl 1):P108.

\section{Submit your next manuscript to BioMed Central} and take full advantage of:

- Convenient online submission

- Thorough peer review

- No space constraints or color figure charges

- Immediate publication on acceptance

- Inclusion in PubMed, CAS, Scopus and Google Scholar

- Research which is freely available for redistribution

Submit your manuscript at www.biomedcentral.com/submit 